Research Article

\title{
High Performance Thin Layer Chromatography Fingerprinting Studies of Croton klotzschianus (Wight) Thw.
}

\author{
Suresh J*1, Saravana Ganthi A ${ }^{2}$ \\ 1PSR College of Education, Sivakasi, Tamil Nadu- 626140, India. \\ ${ }^{2}$ Department of Botany, Rani Anna Govt. College for Women, Tirunelveli, Tamil Nadu, India. \\ *Corresponding author's E-mail: saran_gan@rediffmail.com
}

Received: 22-05-2021; Revised: 25-07-2021; Accepted: 06-08-2021; Published on: 15-08-2021.

\section{ABSTRACT}

Most of the traditional medicinal plants in India are not scientifically validated. Scientific evaluation along with traditional knowledge is essential to obtain effective drugs for commercial purpose. The present study was aimed at High Performance Thin Layer Chromatography (HPTLC) analysis of ethanol extracts of leaf, stem and root of Croton klotzschianus. The chemical fingerprint through HPTLC Studies was carried out as per the standard method. The HPTLC shows ethanolic extracts of Croton klotzschianus at UV short and long wavelength 254 and 366 using Hexane: Ethyl acetate: Toluene: Chloroform: Methanol: Formic acid (4:2.5:1.5:0.8:1:0.2) as mobile phase and the Rf values were recorded. The HPTLC fingerprint profile of leaf, stem and root extracts was exhibits 12 peaks each. The results of qualitative phytochemical screening confirm the presence of flavonoids. The HPTLC analysis to help in proper identification and quantification of marker compounds.

Keywords: Croton klotzschianus, Ethanol extracts, Flavonoid, Fingerprint, HPTLC.

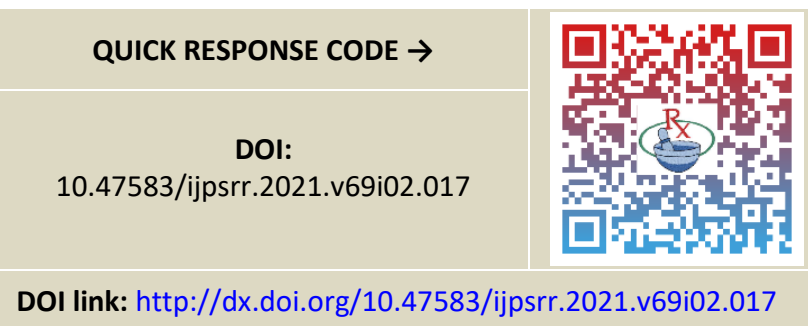

\section{INTRODUCTION}

$\mathrm{P}$

hytomedicines are the products made from plants, which are used to treat diseases or to maintain health. Traditional systems of Medicines have a history of more than 3000 years ${ }^{1}$. Even today in developing countries a large sections of the population still depend on herbal medicines for their primary care. In Africa up to $90 \%$ and in India $70 \%$ of the population depend on traditional medicine to help meet their health care needs ${ }^{2}$. Global Herbal Medicine market is expected to grow at a compound annual growth rate (CAGR) of $7.2 \%$ during Period of 2017 to 2023. Annual global Nutraceuticals market should extent $\$ 285.0$ billion by 2021 from $\$ 198.7$ billion in 2016 at CAGR of 7.5\%, from 2016 to 2021.The Herbal Medicine market is estimated to be valued at USD $1,29,689.3$ million by 2023 and expected to grow at a CAGR of $5.88 \%$ during $2018-2023^{3}$. The global Herbal Medicine market size is expected to reach USD 411.2 billion by 2026 and is anticipated to grow at a CAGR of $20.5 \%$ from 2020-20264. Overall international trade in medicinal plants and their products was US\$ 60 billion in 2010 and is expected to reach US\$ 5 trillion by $2050^{5}$. The rapid increasing demand on herbal plants trade requires the quality evaluation of phytoconstituents of herbal products. High-performance thin-layer chromatography (HPTLC) establishes the identity, purity, quality, and stability of raw materials, extracts, and finished botanical products. Croton klotzschianus (Wight) Thw. is a peninsular endemic plant belonging to the family Euphorbiaceae. It is a deciduous shrub occurs in river banks of foot hills of Western Ghats. Croton species are traditionally used to treat various ailments such as, cancer, constipation, diabetes, stomach related issues, loose bowels, outside injuries, fever, hypercholesterolemia, hypertension, aggravation, intestinal worms, malaria, torment, ulcers and weight reduction ${ }^{6}$. The main objective of the present study to develop a High-performance thin-layer chromatographic fingerprint of ethanol extract of dried powdered samples of Croton klotzschianus. This will be useful for authentication and identification chosen plant in future.

\section{MATERIALS AND METHODS}

\section{Plant materials}

Fresh and diseased free Croton klotzschianus was collected from Courtallum, Hills, Tirunelveli, Tamil Nadu. Plant was authentified with Flora of Presidency of Madras ${ }^{7}$ and Flora of Tamil Nadu Carnatic ${ }^{8}$. Specimen voucher of the plants are kept at the Xavier's College Herbarium (XCH 26587), St. Xavier's College (Autonomous), Palayamkottai, Tirunelveli, Tamil Nadu. Plant materials such as leaf, stem, root were shade dried and powdered separately.

\section{Preparation of extract}

50 gram of powdered plant materials were extracted in soxhlet apparatus with the chromatographic grade solvent of ethanol. The extracts were filtered through Whatman filter paper and concentrated. 


\section{HPTLC analysis}

HPTLC instrument of CAMAG, Muttenz, Switzerland, Anchrom Enterprises (I) Pvt. Ltd, Mumbai was used in the present study. It consisting of sample applicator (Linomat $5)$, Twin trough chamber with lid $\{10 \times 10 \mathrm{~cm}$, CAMAG, Muttenz, Switzerland\}, UV cabinet (Aetron, Mumbai) with dual wavelength $(254 / 366 \mathrm{~nm})$ and the HPTLC photo documentation (Aetron, Mumbai) was used for study.

HPTLC studies were carried out following the method of Harborne ${ }^{9}$.The prepared sample of leaf, stem and root extracts were applied separately at the concentration of $10 \mu \mathrm{L}$ using the applicator and set at a speed of $150 \mathrm{nl} / \mathrm{sec}$. The mobile phase was Hexane: Ethyl acetate: Toluene: Chloroform: Methanol: Formic acid (4:2.5:1.5:0.8:1:0.2) and the stationary phase was aluminum precoated sheets, Silica Gel G 60 F254 (Merck). The applicator phase was CAMAG LINOMAT 5. Plate was developed in a twin trough chamber. The active compounds are detected by spraying with Anisaldehyde sulfuric acid reagent and heat at $110^{\circ} \mathrm{C}$ for 5 minutes. The plate was scanned at 254 and $366 \mathrm{~nm}$ under fluorescent mode. After each observation the central points of spots appeared on chromatogram were marked with needle. The Rf values and finger print data were recorded by WIN CATS software.

\section{RESULTS}

Fingerprinting is a useful tool for the quality control of herbal products ${ }^{10}$ and HPTLC fingerprinting provides an objective source to compare and identify substances ${ }^{11}$.

\section{HPTLC Analysis}

High Performance Thin Layer Chromatography fingerprinting analysis was carried out based on the above procedure. The bands were observed on the HPTLC plates. The $\mathrm{Rf}$ values were calculated. In dried leaf powder extract of C. klotzschianus reported 12 peaks, with different $\mathrm{R}_{f}$ values $(0.16,0.17,0.23,0.29,0.43,0.46,0.51,0.61,0.67$, $0.78,0.82,0.83)$ and area percentage $(150.4,223.4,629.1$, 34.7, 112.4, 138.3, 813.9, 796.2, 57.2, 264.6,294.2, 320.4) with the mobile phase Hexane: Ethyl acetate: Toluene: Chloroform: Methanol: Formic acid (4:2.5:1.5:0.8:1:0.2) (Table 1). The significant peak is observed at $R_{f} 0.51$ with the percentage area of 813.9 (Fig: 1).

Ethanol extract of stem powder of $C$. klotzschianus shows 12 polyvalent phytoconstituents and corresponding ascending order of $\mathrm{R}_{f}$ values start from 0.16 to 0.85 in which highest concentration of the phytoconstituents is found to be 38.4 and its corresponding $R_{f}$ value is found to be 0.85 respectively and is recorded in Table 2 . The corresponding HPTLC chromatogram is presented in Fig: 2. The mobile phase was Hexane: Ethyl acetate: Toluene: Methanol: Formic acid (4:2.5:1.5:0.8:1:0.2).

In high performance, thin layer chromatography analysis (on Aluminum coated Silica Gel - Merck F 254) of $C$. klotzschianus, ethanol extract of root sample gave 12 bands with $\mathrm{R}_{f}$ value ranged from 0.16 to 0.82 (Fig 3). The peak at $R_{f}$ value 0.49 shows the maximum concentration with an area 715.7 (Table. 3) obtained in the mobile phase Hexane: Ethyl acetate: Toluene: Methanol: Formic acid $(4: 2.5: 1.5: 0.8: 1: 0.2)$.

\section{DISCUSSION}

Similar to present report previously many HPTLC fingerprinting analysis were carried out in Euphorbiaceae, such as Croton gratissimus ${ }^{11}$; Jatropha curcas $^{12}$; Euphorbia hirta ${ }^{13}$; Putranjiva roxburghiii ${ }^{14}$; Pedilanthus tithymaloides $^{15}$; Phyllanthus amarus ${ }^{16}$; Flueggea virosa ${ }^{17}$; Amla ${ }^{18}$. The study is carried out with HPTLC and the results showed that there are many compounds in $C$. klotzschianus. From the HPTLC studies, it has been found that ethanol extracts contain not a single compound but a mixture of compounds. So, the pharmacological activity shown by the chosen plant may be due to synergesic effect of all the compounds in extract. Several peaks observed in this HPTLC analysis indicated the diverse composition of the extracts.

Table 1: HPTLC analyses of leaf ethanol extract of Croton klotzschianus (Wight) Thw.

\begin{tabular}{|c|c|c|c|c|c|}
\hline S. No. & Rf & Height & Area & $\begin{array}{c}\text { Lambda } \\
\text { Max }\end{array}$ & $\begin{array}{c}\text { Assigned } \\
\text { substance }\end{array}$ \\
\hline 1 & 0.16 & 13.0 & 150.4 & 348 & Unknown \\
\hline 2 & 0.17 & 11.4 & 223.4 & 314 & Flavonoid 1 \\
\hline 3 & 0.23 & 16.4 & 629.1 & 277 & Unknown \\
\hline 4 & 0.29 & 1.2 & 34.7 & 277 & Unknown \\
\hline 5 & 0.43 & 3.8 & 112.4 & 277 & Unknown \\
\hline 6 & 0.46 & 7.0 & 138.3 & 277 & Unknown \\
\hline 7 & 0.51 & 17.1 & 813.9 & 277 & Flavonoid 2 \\
\hline 8 & 0.61 & 22.1 & 796.2 & 237 & Unknown \\
\hline 9 & 0.67 & 1.8 & 57.2 & 127 & Unknown \\
\hline 10 & 0.78 & 7.2 & 264.6 & 277 & Kaempferol \\
\hline 11 & 0.82 & 8.8 & 294.2 & 277 & Flavonoid 3 \\
\hline 12 & 0.83 & 8.9 & 320.4 & 277 & Unknown \\
\hline
\end{tabular}

Table 2: HPTLC analyses of stem ethanol extract of Croton klotzschianus (Wight) Thw.

\begin{tabular}{|c|c|c|c|c|c|}
\hline S. No. & Rf & Height & Area & $\begin{array}{c}\text { Lambda } \\
\text { Max }\end{array}$ & $\begin{array}{c}\text { Assigned } \\
\text { substance }\end{array}$ \\
\hline 1 & 0.16 & 10.7 & 110.9 & 208 & Unknown \\
\hline 2 & 0.17 & 8.4 & 121.4 & 277 & Flavonoid 1 \\
\hline 3 & 0.24 & 0.7 & 12.2 & 277 & Unknown \\
\hline 4 & 0.28 & 2.4 & 42.7 & 277 & Unknown \\
\hline 5 & 0.30 & 2.3 & 55.4 & 277 & Flavonoid 2 \\
\hline 6 & 0.33 & 1.1 & 25.4 & 277 & Unknown \\
\hline 7 & 0.41 & 1.7 & 50.2 & 277 & Unknown \\
\hline 8 & 0.45 & 2.0 & 55.3 & 277 & Unknown \\
\hline 9 & 0.48 & 32.5 & 1234.1 & 283 & Unknown \\
\hline 10 & 0.61 & 10.1 & 399.9 & 277 & Flavonoid 3 \\
\hline 11 & 0.80 & 14.2 & 509.4 & 277 & Unknown \\
\hline 12 & 0.85 & 38.4 & 2455.5 & 262 & Unknown \\
\hline
\end{tabular}


Table 3: HPTLC analysis of root ethanol extract of Croton klotzschianus(Wight)Thw.

\begin{tabular}{|c|c|c|c|c|c|}
\hline S. No. & Rf & Height & Area & $\begin{array}{c}\text { Lambda } \\
\text { Max }\end{array}$ & $\begin{array}{c}\text { Assigned } \\
\text { substance }\end{array}$ \\
\hline 1 & 0.16 & 9.6 & 95.4 & 283 & Unknown \\
\hline 2 & 0.18 & 8.0 & 104.3 & 277 & Unknown \\
\hline 3 & 0.30 & 6.6 & 280.3 & 277 & Flavonoid 1 \\
\hline 4 & 0.39 & 1.5 & 41.1 & 277 & Unknown \\
\hline 5 & 0.43 & 2.7 & 83.5 & 277 & Unknown \\
\hline 6 & 0.49 & 16.69 & 715.7 & 277 & Unknown \\
\hline 7 & 0.55 & 1.2 & 25.2 & 277 & Unknown \\
\hline 8 & 0.62 & 6.5 & 233.1 & 277 & Unknown \\
\hline 9 & 0.64 & 4.2 & 85.2 & 277 & Chlorogenic \\
\hline 10 & 0.68 & 2.2 & 55.3 & 277 & Unkid \\
\hline 11 & 0.78 & 5.6 & 201.5 & 277 & Unknown \\
\hline 12 & 0.82 & 5.9 & 338.6 & 277 & Flavonoid 2 \\
\hline Standard & 0.71 & 6.8 & 364.5 & & Kaempferol \\
\hline
\end{tabular}

The data and HPTLC fingerprint profile could be used as a valuable analytical tool in the quality control and standardization $^{19}$. Further characterization of these fractions by applying more sophisticated separation and purification techniques are necessary to find out the exact chemical compounds and their relation to the pharmacological activity.

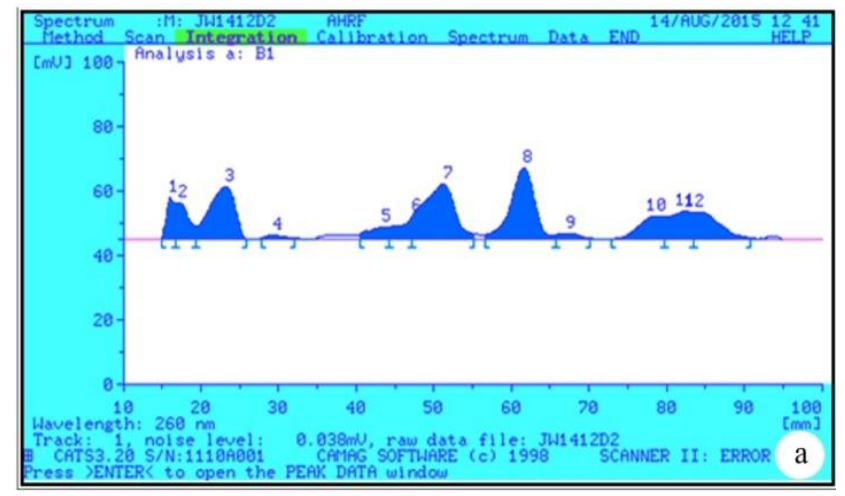

Figure 1: HPTLC Chromatogram of leaf extract

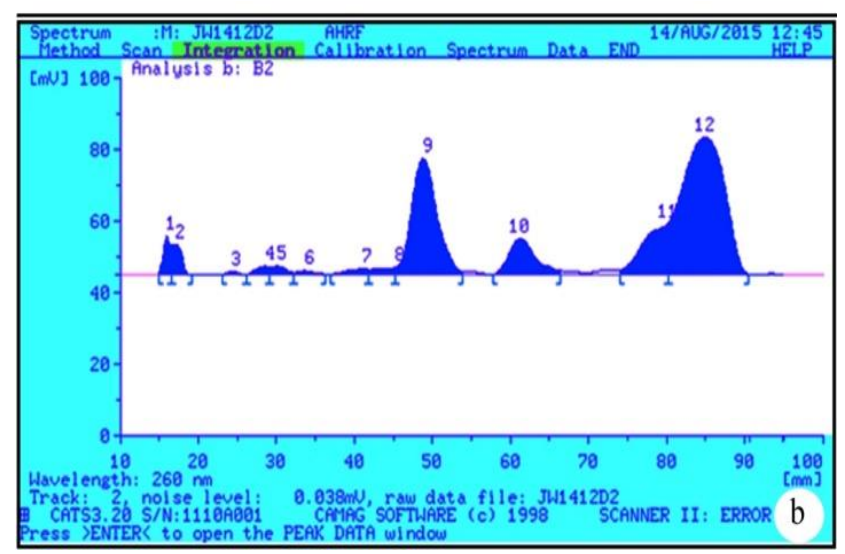

Figure 2: HPTLC Chromatogram of stem extract

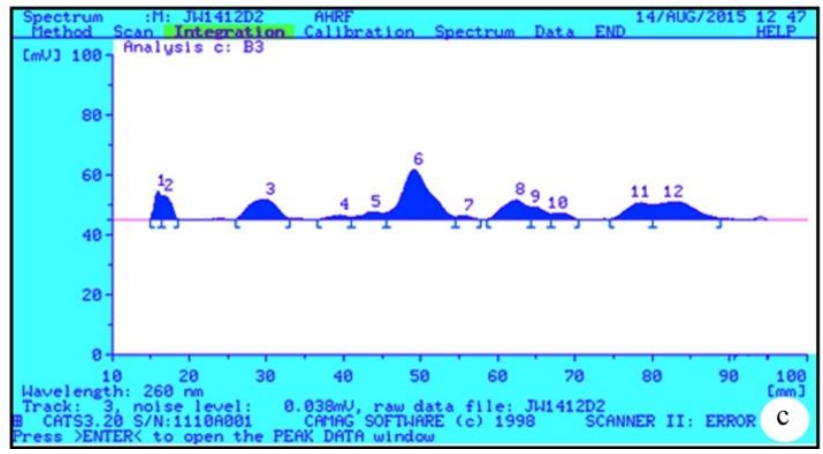

Figure 3: HPTLC Chromatogram of root extract

\section{CONCLUSION}

This present study HPTLC analysis of ethanolic extracts of Croton klotzschianus confirmed the presence of various phytochemicals. HPTLC finger printing profile is very important parameter of herbal drug standardization for the proper identification of medicinal plants. These methods were also employed to analyse commercial samples to illustrate their application in qualitative and quantitative determination, demonstration their possibility in the quality control of phytoconstituents from herbal drugs and formulations. For further study, by developing analytical method pure active chemical compound should be isolated and identified on the basis of standard protocol.

Acknowledgments: The authors are thankful to the Principal, Rani Anna Government College for women, Tirunelveli, Tamil Nadu for providing facilities and encouragement.

\section{REFERENCES}

1. Xutian S, Zhang J, Louise W. New exploration and understanding of traditional Chinese medicine. Am. J. Chin. Med. 2009; 37: 411-26.

2. World Health Organization (WHO): National Policy on Traditional Medicine and Regulation of Herbal Medicines. Geneva: 2005. Report of WHO global survey.

3. www.marketresearchfuture.com.

4. www.medgadget.com.

5. Nirmal SA, Pal SC, Otimenyin SO, Thanda Aye, Mostafa Elachouri, Sukalyan Kumar Kundu, Rajarajan Amirthalingam Thandavarayan, Subhash C. Mandal Contribution of Herbal Products In Global Market. The Pharma Review. 2013; 95 99.

6. Antonio Salatino, Maria L, Faria Salatino, Giuseppina Negri. Traditional uses, Chemistry and Pharmacology of Croton species (Euphorbiaceae). J. Braz. Chem. Soc. 2007; 18 (1): 11-33.

7. Gamble JS. Euphorbiaceae In: Flora of the Presidency of Madras, Adlard and Son, London, (1915-1936).

8. Mathew KM. The Flora of Tamilnadu Carnatic, Vol. 1-3. The Rapinat Herbarium. St. Joseph College, Tiruchirapalli, India, (1983- 1988). 
9. Harborne JB. Phytochemical methods. Edn. $3^{\text {rd }}$ London, Chapman and Hall, 1998; pp: 1-28.

10. Peishan Xie, Sibao Chen, Yi-Zeng Liang, Xianghong Wang, Runtao Tian, Roy Upton. Chromatographic fingerprint analysis-a rational approach for quality assessment of traditional Chinese herbal medicine. Journal of Chromatography. 2006; 12(1-2): 171-180.

11. Pudumo J, Chaudhary SK, Chen W, Viljoen A, Vermaak I, Veale CGL. HPTLC fingerprinting of Croton gratissimum leaf extract with Preparative HPLC-MS-isolated marker compounds. South African Journal of Botany. 2018; 114: 32-36.

12. Shanti Bhushan Mishra, Alok Mukerjee, Vijayakumar M. Pharmacognostical and Phytochemical Evaluation of Leaves Extract of Jatropha curcas Linn. Pharmacognosy Journal. 2010; 2(15): 8 -14.

13. Kalyan Hazra, Sreya Dutta, Shreya Ghosal, Deboleena Paria, Mruthyumjaya Meda Rao. Phytopharmacognostic evaluation of plant Euphorbia hirta L. International Journal of Herbal Medicine, 2019; 7(3): 07-15.

14. Kedar Kalyani Abhimanyu, Chaudhari Sanjay Ravindra, Rao, Srinivasa Avanapu. A validated HPTLC method for the quantification of friedelin in Putranjiva roxburghii Wall extracts and in polyherbal formulations. Bulletin of Faculty of Pharmacy, Cairo University. 2017; 55(1): 79-84.

15. Neetu Soni, Rajani Srivastava. HPTLC fingerprint analysis of Pedilanthus tithymaloides or Euphorbia tithymaloides. The Pharma Innovation Journal, 2019; 8(5): 779-784.

16. Annamalai A, Lakshmi PTV. HPTLC and HPLC analysis of Bioactive Phyllanthin from Different Organs of Phyllanthus amarus. Asian Journal of Biotechnology, 2009; 1: 154-162.

17. Nasir A, Siddiqui, Ramzi A, Mothana, Adnan J, AlRehaily, Perwez Alam, Muhammad Yousaf, Sarfaraz Ahmed, Abdulrahman Alata. High-performance thin-layer chromatography based concurrent estimation of biomarkers ent-phyllanthidine and rutin in the dried aerial parts of Flueggea virosa. Saudi Pharm. J. 2017; 25(5): 696702.

18. Chakraborthy GS. Quantitative Estimation of Ascorbic Acid by HPTLC in different varieties of Amla. Journal of Young Pharmacists. 2009; 1(1): 82-85.

19. Karuppusamy Arunachalam, Murugaiyan Iniyavan, \& Thangaraj Parimelazhagan. A HPTLC Method for the identification of potential Therapeutic Compound of Kaempferol from Ficus amplissima Smith. Int. J. Pharm. Sci. Rev. Res., 2013; 22 (1): 166-171.

Source of Support: The author(s) received no financial support for the research, authorship, and/or publication of this article.

Conflict of Interest: The author(s) declared no potential conflicts of interest with respect to the research, authorship, and/or publication of this article.

For any question relates to this article, please reach us at: editor@globalresearchonline.net

New manuscripts for publication can be submitted at: submit@globalresearchonline.net and submit_ijpsrr@rediffmail.com 